\title{
Study on Earthquake and Fire Prevention of the Building Village in the City
}

Jiangsu Province Rudong County Housing and Urban and Rural Construction Bureau Jiangsu Nantong 226400

\section{Introduction}

Earthquake can be said to be "the first disaster", in many disasters caused by the greatest loss. The earthquake can cause a wide range of damage in a short time, to people's lives and has brought some impact to the social development. The occurrence of earthquake disaster will cause the reduction of urban population and to bring huge losses to the social economy, serious damage to the ecological environment, which can be considered as a major threat to the development of modern urban construction in the $21^{\text {st }}$ century. China is one of the two most active earthquake zones in the world, namely the Central Pacific volcanic seismic belt and the Eurasian seismic zone, which leads to China becoming one of the countries affected by the earthquake disaster.

\section{Village in the city's building earthquake prevention}

\subsection{Requirements for unstruc- tured components}

Engineering seismic design of non-structural components is the need for relevant personnel. The nonstructural construction of the building structure and the roof structure should be effectively connected with the main components of the building to avoid the collapse of these non-structural members during the earthquake or the smashing of important facilities. Construction of the wall and partition wall in the construction process should strengthen the adverse effects of seismic structure con- siderations, effectively avoid the unreasonable setting and lead to contact with the main structure of the project damage. In the curtain wall, decorative veneer construction should ensure that it has a reliable connection with the main structure to prevent the earthquake occurred in the process of curtain wall, decorative veneer fell off the injured residents of the situation. In the construction of ancillary machinery and electrical equipment installed underground process should ensure that the reliability of the production and connection, which should meet the specific requirements of seismic and should not damage the corresponding parts.

\subsection{Set a reasonable high-rise concrete building structural pa- rameters}

In the course of the construction of the city in the process of modeling the earthquake occurred when the high-rise building concrete of the various forces, set reasonable parameters of the building structure, calculation and analysis the force of the structure, such as calculating the deformation of the main beam, wall load capacity and so on. In the high-rise building concrete structure seismic planning and design, which should strengthen the construction of the quality of construction testing, has a clear level of construction technology, high quality construction materials used in the construction site and understanding the actual situation at the construction site in order to master the seismic design of the main points of construction. Construction
Abstract: With the process of urbanization accelerating, most of the original villages were included in the process of urban construction, because of the rural construction process, and not synchronized with the city management, which led to the phenomenon of an urban village, and led to various problems in the process of urban construction. "Village in the city" phenomenon not only affects the image of the city in the development process, but also affecting the city in the future development process, so most of the planning staff in the city when the induction of it and did not imply in the "village the city" planning. To the process of urban construction, so that "the village" in the construction process of the lack of appropriate management, which cannot effectively solve the management process arising from a variety of problems. Especially in particular part of the "village" housing construction in the earthquake prevention and fire prevention, which brought a certain degree of danger should be emphasized in this regard.

Key words: Village in city; building; earthquake prevention; fire prevention problem

Published online: 15th July, 2017 
of the basic framework of the seismic performance of the design to optimize the design of the construction drawings in the process, the key location information should be indicated in the construction drawings, and gradually optimize the seismic design of construction. The establishment of accurate and precise seismic design database, so that during the design of the building, you can query the database for relevant data and engineering cases, which includes the force in the construction of building to giving an accurate analysis and based on the data obtained from the design engineering force model, use of the main tensile stress and modeling theory for the scientific analysis of the force of the construction project and a reasonable design of the seismic performance of the building.

\subsection{Plane layout design of the build- ing}

In the process of building design, the layout of the building is a very important work. If a building with a good layout, then the use of the construction performance will be very good, and the rational layout of the construction plane. The construction layout has a certain impact on the seismic performance. After the analysis of the important role of the seismic design of the building in the design process, the first thing to be done is to ensure the rigidity of the building and the quality of the construction work. In the process of plane arrangement, the mutual symmetry between the two should be ensured comparably to avoid the building structure because of the different forces and deformation of the situation. The seismic force of the construction of the wall must be coordinated with the seismic structure. It should be more rigid building space floor and a high strength of the construction of the elevator to the construction of the central location to prevent the construction of the structure of the reverse effect. In the process of plane layout can- not ignore the construction of anti-lateral structure of the layout, so what to ensure the use of construction performance and construction of the seismic performance will not be affected by the good play of the seismic design of the advantages of construction.

\section{Village in the city building fire prevention}

\subsection{Strict restrictions on the use of buildings in the city}

"Village in the city" in the construction process, will involve many aspects. In the "village in the city" building fire prevention design process should strictly follow the "prevention as the main idea and fire protection in combination" principle for the development of fire safety policy. In the process of "village in the city" construction, some construction units and staff in order to be able to effectively enhance their own economic benefits, which including during the construction process, often not in accordance with the relevant provisions of the flammable, explosive Grade A factories or buildings near the construction of houses or homes. These plants are prone to fire situation and in the event of a fire, its scope of influence becomes larger. In the relevant provisions, in the presence of large fire hazards near the plant is not allowed to build a new type of residential. In order to ensure the safety of the residents, in the "village in the city" construction of the project, it should choose the relevant safety distance for the construction and the effective prevention of fire after the occurrence of large-scale impact. Therefore, in the process of construction of the site selection is very important to ensure the safety of people's lives and reduce the impact of fire has a very important role.

\subsection{Set fire station}

In order to effectively reduce the impact of fire on the construction project to ensure the safety of life and property of the residents in the process of "village in the city" construction, because the fire setting is not perfect, the population and buildings are over-concentrated, the fire department after receiving the fire alarm call within 5 minutes must reach the location of the fire point and start firefighting operations, which for the fire department is very important. Under normal circumstances, in the process of urban construction, according to the risk of fire, every 4000-7000 square meters within the scope of the need to divide by a fire station and its effective management, but in the "village" construction in the process, the building's fire-resistant grade is only three or four. To this end, in the process of construction, it must be based on the actual situation of the construction area of the fire station to effectively divide, while the fire station should be set in the convenient transportation area, so easy to fire-fighting when the timely warning. However, taking into account the fire alarm to the surrounding people to bring the psychological impact of the fire station should be established in the distance school, kindergarten, hospitals and other public facilities 20 meters away from the place.

In short, in recent years with the urbanization process continues to accelerate, people on the construction's qualities and requirements are higher. Fire prevention and seismic design are a very important content, through the construction of the various factors of construction analysis. Reasonable to optimize the construction of fire prevention and seismic design for improving the quality of construction projects, which can effectively guarantee the safety of people living environment.

\section{References:}

[1] Man Guojun, Fu Yi Xuan. On the High-Rise Concrete Building Seismic Structure Design [J]. Henan Science 
and Technology, 2013,12: 168.

[2] Zhang Quanzhen. Architectural Design in the Building Seismic Design of the Important Role [J]. Doors and windows, 2014 (9).
[3] Zou Songgui. Design and Analysis of Seismic Structure of High-Rise Concrete Building [J]. Industry and Technology Forum, 2012,23: 67. 